\title{
Compuestos Volátiles Producidos in Vitro por Callos de Solanum quitoense Lam. (Solanaceae)
}

\author{
Volatiles Compounds Produced in Vitro by Callus of Solanum quitoense Lam. \\ (Solanaceae)
}

A. M. Duarte-Hernández ${ }^{\mathrm{a}, *}$

K. M. Núñez ${ }^{\mathrm{b}}$

J. C. Pacheco ${ }^{\mathrm{b}}$

J. J. Martínez

Recepción: 02-jun-13

Aceptación: 21-ago-13

\section{Resumen}

En la búsqueda de fuentes no convencionales para la obtención de compuestos volátiles se ha recurrido a la biotecnología vegetal. Este estudio describe el efecto de diferentes concentraciones de ácido naftalén-acético (ANA), usado en la inducción de callos de Solanum quitoense Lam., sobre la producción de compuestos volátiles. A partir de callos cultivados durante 30, 40 y 50 días se evaluó, por cromatografía de gases acoplada a espectrometría de masas (CGAR-EM), la composición volátil de los compuestos extraídos mediante microextracción en fase sólida (MEFS) o extracción líquida-líquida; los resultados muestran la presencia de 30 compuestos volátiles, en los que se destacan notas sensoriales a verde y dulce.

Palabras clave: Callos, Solanum quitoense Lam., Compuestos volátiles, Lulo, Naranjilla.

\begin{abstract}
Vegetal biotechnology has been used, in the non-conventional sources search, in order to obtain volatiles compounds. This study describes the naphthaleneacetic acid (NAA) different concentrations effects, on the callus from Solanum quitoense Lam. induction, in the volatile organic compounds production. The volatile composition was analyzed by a gas chromatography, coupled to a mass spectrometry on a callus cultured during 30, 40 and 50 days, in which were subject to a solid phase micro extraction (HS-SPME) or a liquid-liquid extraction, in which 30 volatile compounds were identified. Green and sweet sensorial notes were detected in the callus cultures.
\end{abstract}

Key words: Callus, Solanum quitoense Lam., Volatiles Compounds, Lulo.

\footnotetext{
${ }^{a}$ Departamento de Química, Centro de Investigación y Estudios Avanzados del Instituto Politécnico Nacional, D. F., México. ${ }^{b}$ Facultad de Ciencias Básicas, Universidad Pedagógica y Tecnológica de Colombia Uptc, Tunja, Boyacá-Colombia.

*Autor de correspondencia: aduarte@ cinvestav.mx
} 


\section{Introducción}

La composición volátil de tejidos de Solanum quitoense Lam. ha sido estudiada por varios autores debido a su atractivo aroma, constituido por distintos compuestos de tipo monoterpénico, alcoholes, aldehídos, lactonas, ácidos, hidrocarburos alifáticos y éteres aromáticos, entre otros [1,2]; como componentes mayoritarios, en conjunto proporcionan un placentero y exquisito aroma al fruto del lulo, importante en la industria de alimentos, aromas y fragancias [3]; sin embargo, la obtención natural de este aroma involucra una cantidad apreciable de materia prima, lo cual no hace rentable este proceso.

En la búsqueda de nuevas alternativas para la obtención de aromas, se ha estudiado la posibilidad de usar la biotecnología vegetal como fuente alternativa en la producción de metabolitos secundarios. Se debe destacar que para la producción de compuestos volátiles a partir de cultivos in vitro es necesario monitorear la biosíntesis de estos compuestos, para favorecer las condiciones idóneas para su producción en altos rendimientos, así como una excelente elección de las metodologías analíticas que permiten una extracción eficiente de los componentes de interés [4].

Actualmente, existen estudios sobre la obtención y caracterización de volátiles en diferentes especies de plantas cultivadas in vitro, entre otras, Citrus sinensis (L.) [4, 5], Zataria multiflora Boiss [6], Agastache rugosa Kuntze (Korean mint) [7], Carum copticum [8], Salvia officinalis L. [9], Rosadamascena Mill [10], Santolina chamaecyparissus [11], Mentha piperita [12], Thymus vulgaris L. [13], Camellia sinensis [14] y Plectranthus ornatus Codd [15]; sin embargo, no existen trabajos relacionados en frutos tropicales en la obtención de volátiles por cultivos de tejidos vegetales. Por lo tanto, se realizó el estudio de la caracterización volátil producida por cultivos de callos de lulo, por medio de dos métodos de extracción: Extracción Líquido-Líquido (ELL) y Microextracción en Fase Sólida (MEFS).

\section{Experimental}

\subsection{Cultivo de callos}

Los callos del lulo, Solanum quitoense Lam., suministrados por el Laboratorio Bioplasma-UPTC), fueron obtenidos de explantes tomados de hojas, pe- ciolos y tallos procedentes de plántulas mantenidas en condiciones in vitro. Los explantes se cultivaron en medio MS (Murashige y Skoog, 1962), al cual se le adicionaron $3.0 \mathrm{~g} / \mathrm{L}$ de sacarosa, $6.5 \mathrm{~g} / \mathrm{L}$ de agar y $0.5,1.0$ o $2.0 \mathrm{mg} / \mathrm{L}$ de ANA (ácido naftalén-acético). El pH del medio se ajustó a 5.6 con $\mathrm{NaOH}$ o $\mathrm{HCl}$ $(0.5-1.0 \mathrm{~N})$, y se esterilizó en autoclave a $121{ }^{\circ} \mathrm{C}$ y 15 PSI de presión durante 20 minutos. Los cultivos se incubaron en oscuridad continua a $23{ }^{\circ} \mathrm{C}$. Los callos se colectaron después de 30, 40 y 50 días de haber sido transferidos a medio fresco, y se agruparon así: C1: Callos,procedentes de pecíolos, colectados después de 30 días; C2: procedentes de hojas y tallos, colectados después de 40 días, y C3: procedentes de hojas, tallos y pecíolos, colectados después de 50 días.

\subsection{Análisis de la biomasa}

\subsubsection{Microextracción en fase sólida (MEFS)}

Los callos de cada tratamiento (C1, C2 y C3) se colocaron en viales de $300 \mathrm{~mL}$, cerrados herméticamente con septas. La extracción de volátiles por MEFS se realizó con una fibra de polidimetilsiloxano (PDMS) $(100 \mu \mathrm{M})$ bajo las siguientes condiciones: tiempo de equilibrio: 1 hora; temperatura: $25^{\circ} \mathrm{C}$; tiempo de muestreo: 2 horas; tiempo de desorción: 5 minutos; temperatura de desorción: $200{ }^{\circ} \mathrm{C}$.

\subsubsection{Extracción líquido-líquido (Extracción $L-L$ )}

Para el análisis de los compuestos volátiles producidos por los callos se preparó una suspensión homogénea de $10 \mathrm{~g}$ de biomasa fresca en $20 \mathrm{~mL}$ de agua destilada a temperatura ambiente. La suspensión se centrifugó a 12.000 rpm durante 5 minutos, luego de lo cual se sometió a ELL durante 72 horas, utilizando una mezcla de pentano-diclorometano 1:1 $\mathrm{v} / \mathrm{v}$ como solvente. El extracto obtenido fue secado con sulfato de sodio anhidro y concentrado a un volumen aproximado de $200 \mu \mathrm{l}$ para el posterior análisis por cromatografía de gases de alta resolución acoplada a espectrometría de masas (CG-EM).

\section{Cromatografía de gases acoplada a espectro- metría de masas (CG-EM)}

Se utilizó un cromatógrafo de gases Hewlett Packard 5890 serie II equipado con un detector selectivo de masas HP 5970. La introducción de la muestra 
se hizo en modo splittless con una columna en sílica fundida con fase estacionaria DB-Wax (25 $\mathrm{m}$ x 0.25 mm d.i., $\mathrm{df}=0.25 \mu \mathrm{m})$. La temperatura en el horno fue programada así: $50{ }^{\circ} \mathrm{C}$ durante 4 minutos y luego calentamiento hasta $200{ }^{\circ} \mathrm{C}$ a una velocidad de 4 ${ }^{\circ} \mathrm{C} / \mathrm{min}$. La temperatura del inyector y del detector se mantuvo en $200{ }^{\circ} \mathrm{C}$. Los espectros de masas se tomaron en el modo de impacto electrónico con una energía de ionización de $70 \mathrm{eV}$, y la temperatura de la interfase se mantuvo en $200{ }^{\circ} \mathrm{C}$. El intervalo de masas para la adquisición fue 30-350 uma.

\section{Resultado y discusión}

\subsection{Cultivo de callos}

El medio MS facilitó la viabilidad de los tejidos utilizados como explantes primarios, y las diferentes concentraciones de ANA promovieron el proceso de diferenciación y división celular. El grado de compactación de la biomasa necesaria se logró con la aplicación de ANA en el medio de cultivo, observándose la formación de callos-masas y con crecimiento continuo a una concentración de $1 \mathrm{mg} / \mathrm{L}$. La producción de biomasa fue más abundante a partir de explantes de tallo que de hoja y pecíolo. En presencia de $0,5 \mathrm{mg} / \mathrm{L}$ de ANA, la diferenciación fue lenta y los callos obtenidos fueron compactos; al aplicar 2,0 $\mathrm{mg} / \mathrm{L}$ se observó una diferenciación celular rápida y la proliferación más activa que en las anteriores. El crecimiento de la biomasa disminuyó drásticamente entre los 20 y 30 días en los tres tratamientos.

\subsection{Análisis de la biomasa}

El aislamiento de los volátiles de las masas celulares es un proceso bastante complejo; la metodología SPME es usada en este tipo de estudios [4], sin embargo, los cromatogramas obtenidos por esta técnica demostraron que no existe una adsorción selectiva con el tipo de fibra empleada (PDMS, $100 \mu \mathrm{M}$ ), presumiblemente debido a que no pueden retener analitos pequeños C2-C9, compuestos similares a los encontrados por extracción líquido-líquido (ELL), usando una mezcla de pentano-diclorometano.

El análisis de los extractos obtenidos por ELL permitió la detección de 30 compuestos, de los cuales fueron identificados 22 con base en los criterios cromatográficos (índice de Kovatz) y espectrales (análisis de los espectros de masas), y en su respectiva comparación con trabajos realizados en tejidos in vivo de lulo $[1,3,16]$. En la tabla 1 se presenta la identidad de los compuestos detectados, así como los índices de retención experimentales y las concentraciones relativas de los constituyentes volátiles en cada uno de los grupos C1, C2 y C3 colectados en 30, 40 y 50 días de cultivo.

En general, los cultivos celulares in - vitro (callos) presentan notas sensoriales a verde con un ligero olor a notas dulces, debido, posiblemente, a la mezcla de diferentes compuestos orgánicos, como alcoholes, obtenidos en mayor proporción (10 compuestos), seguidos por cetonas y, en baja concentración, ésteres (lactonas) y ácidos carboxílicos.

En las tres fracciones de biomasas (C1, C2 y C3) se observaron diferencias en la producción y tipo de los constituyentes volátiles presentes. En $\mathrm{C} 1$, por ejemplo, se obtuvieron 19 compuestos, y en C2 y C3 hubo menor producción de los volátiles, debido a un bajo estado de desarrollo de las biomasas celulares y a los periodos de estrés causados por la disminución de nutrientes del medio de cultivo, que son indispensables para el desarrollo de todos los procesos metabólicos.

De los compuestos volátiles identificados en las tres fracciones $(\mathrm{C} 1, \mathrm{C} 2$ y $\mathrm{C} 3)$ es de importancia destacar la presencia de (E)-2-butenol, derivado de la $\beta$-oxidación de los ácidos grasos por reacciones de biotransformación ocurridas en las rutas biosintéticas, obtenido en la fracción C2, así como el monoterpeno hotrienol, proveniente de su intermediario glicosídico R-(-)-2,6-dimetil-3 (E), 7-octadien-2,6diol 6-O- $\beta$-D-glucopiranosido [3, 16], debido a su gran contribución en el aroma característico del fruto de Solanum quitoense Lam., tal como fue establecido en estudios previos de la pulpa y cascara del fruto de lulo [17].

Los resultados obtenidos con callos de Solanum quitoense Lam. permiten corroborar que las células indiferenciadas son incapaces de sintetizar y acumular compuestos volátiles al igual que en la planta intacta [11]. Aunque el cultivo de tejidos vegetales aprovecha la totipotencia celular, según la cual las células en cultivo in vitro podrían producir los mismos metabolitos que la planta entera [18], los perfiles aromáticos de los callos de Solanum quitoense Lam. analizados son diferentes al perfil que se producen en los cultivos in vivo, según lo reportado en la li- 
Tabla 1. Compuestos volátiles obtenidos por ELL produccidos in vitro por callos de Solanum quitoense Lam.

\begin{tabular}{|c|c|c|c|c|c|c|}
\hline & N. ${ }^{\circ}$ & Compuesto & TR & IR & ID & Ref. \\
\hline \multirow[t]{19}{*}{$\mathrm{C} 1$} & 1 & 2-metil-1-propanol & 7,33 & 1149 & $a, b$ & {$[3]$} \\
\hline & 2 & Acetato de etilo & 10,17 & 1241 & $\mathrm{~b}$ & \\
\hline & 3 & 3-hidroxi-2-butanona & 11,00 & 1287 & $\mathrm{a}, \mathrm{b}$ & [3] \\
\hline & 4 & (E)-2,4-Hexadienol & 14,50 & 1364 & $a, b$ & [3], [17] \\
\hline & 5 & (E)-2-hexenol & 15,53 & 1392 & $a, b$ & {$[3],[17]$} \\
\hline & 6 & Sin identificar & 25,11 & 1683 & & \\
\hline & 7 & (Z)-6-nonenol & 27,14 & 1759 & b & \\
\hline & 8 & Sin identificar & 34,34 & 2016 & & \\
\hline & 9 & $\gamma$-dodecalactona & 40,20 & 2263 & $\mathrm{a}, \mathrm{b}$ & [3] \\
\hline & 10 & Sin identificar & 40,42 & 2271 & & \\
\hline & 11 & Sin identificar & 40,91 & 2256 & & \\
\hline & 12 & Sin identificar & 41,28 & 2304 & & \\
\hline & 13 & Ácido 3-hidroxi-tetradecanoico & 42,31 & 2343 & $\mathrm{a}$ & \\
\hline & 14 & $n$-hexadecanal & 43,02 & 2369 & a & \\
\hline & 15 & Ácido benzoico & 44,32 & $>2400$ & $a, b$ & {$[3],[1]$} \\
\hline & 16 & 6-hidroxi-2-hexanona & 44,92 & $>2400$ & $a, b$ & [3], [1] \\
\hline & 17 & Trietil citrato & 45,00 & 2013 & $a, b$ & \\
\hline & 18 & Vainillina & 40,05 & 2257 & $a, b$ & [3], [1] \\
\hline & 19 & 1- octadecanol & 51,08 & $>2400$ & $\mathrm{~b}$ & \\
\hline \multirow[t]{5}{*}{$\mathrm{C} 2$} & 20 & (E)-2-Butenol & 7,33 & 1149 & $a, b$ & \\
\hline & 21 & Alcohol bencílico & 30,57 & 1878 & $a, b$ & [3], [1] \\
\hline & 22 & Trietil citrato & 45,74 & 2013 & $a, b$ & \\
\hline & 23 & Ácido n-octadecenoico & 47,17 & $>2400$ & $a, b$ & \\
\hline & 24 & Sin identificar & 34,22 & 2014 & & \\
\hline \multirow[t]{6}{*}{$\mathrm{C} 3$} & 25 & 2-metil-3-butenol & 5,15 & 1085 & $a, b$ & \\
\hline & 26 & (E)-2-Butenol & 7,29 & 1155 & $a, b$ & \\
\hline & 27 & Sin identificar & 18,82 & 1488 & & \\
\hline & 28 & Hotrienol & 22,16 & 1591 & $\mathrm{a}, \mathrm{b}$ & [16], [3] \\
\hline & 29 & 3-metil-2-propenil ester & 22,40 & 1598 & $\mathrm{~b}$ & \\
\hline & 30 & Sin identificar & 23,68 & 1642 & & \\
\hline
\end{tabular}

TR: Tiempo de retención. IR: Índice de retención experimental medido sobre columna Carbowax.

ID: Identificación por a. Comparado con espectros de masas y b. Comparado con índices de retención de la literatura. Ref.: Compuestos volátiles reportados en la literatura la literatura en diferentes partes de la planta de Solanum quitoense Lam.

teratura $[1,2,3,16]$. De hecho, la mayoría de los compuestos identificados en los cultivos de callos de Solanum quitoense Lam. no se presentan en los tejidos in vivo; observaciones similares encontradas en cultivos in vitro de Santolina chamaecyparissus L. y Carum copticum $[8,11]$ sugieren que algunos procesos de diferenciación celular son requeridos para la síntesis y acumulación de compuestos volátiles.

Se ha reportado que la producción controlada de metabolitos secundarios en tejidos o células cultivadas en condiciones in vitro presenta algunas dificultades debido a la inestabilidad de las líneas celulares o callogénicas (grado de diferenciación que alcanzan las células cultivadas in vitro), las cuales pueden causar bajos rendimientos en la producción de compuestos volátiles, comparados con los rendimientos en la planta intacta $[19,20]$.
Siendo el aroma parte del metabolismo secundario, su producción en cultivos in vitro está asociada a la inducción de diferenciación morfológica o creación de sitios de acumulación artificial. La falta de diferenciación celular hace que la célula siga diferentes caminos metabólicos y que no existan sitios de almacenamiento de compuestos; en consecuencia, habrá una rápida metabolización de los monoterpenos, pues buena parte de estos compuestos son responsables de toxicidad celular [21]; esto ha sido discutido en cultivos celulares de Pelargonium fragans, donde se ha demostrado que toleran monoterpenos en el medio hasta una concentración de 0,1 $\mathrm{g} / \mathrm{L}$ [21]. Quizá esta es la causa de la poca cantidad de monoterpenos encontrados en las distintas fases celulares de los callos de lulo.

También debe tenerse en cuenta que la biosíntesis de algunos metabolitos secundarios es afectada por 
el tipo de explante usado y por los reguladores utilizados en la preparación de los medios de cultivo y sus concentraciones específicas [22], lo cual puede explicar en parte, las diferencias encontradas entre $\mathrm{C} 1, \mathrm{C} 2$ y $\mathrm{C} 3$, indicando que las dos últimas presentaron menor cantidad de compuestos volátiles y, por tanto, bajos niveles de acumulación, condiciones que no permitieron la detección por microextracción en fase sólida. Esta técnica es especialmente útil para la detección de monoterpenos libres, y podría ser una herramienta útil para el seguimiento in situ de la producción de este tipo de compuestos [5, 23].

$\mathrm{El}$ hecho de que las células individuales en estados fisiológicos diferentes respondan de manera diferencial al medio que las rodea, lo cual, a menudo, lleva a la variabilidad en la producción de metabolitos, en vez de ser una dificultad representa una oportunidad para producir líneas celulares de alto rendimiento del compuesto de interés [24]; la ventaja solo es posible si se logran seleccionar las células a través de métodos analíticos, sencillos y confiables.

\section{Conclusiones}

La formación de callos de Solanum quitoense Lam. se logró con crecimiento continuo en presencia de 1 mg/L de Ácido Naftalén Acético (ANA); sin embargo, estas masas celulares son incapaces de sintetizar y acumular compuestos volátiles en una proporción similar a los producidos por cultivos in vivo. En los primeros estados fisiológicos de los callos se produce mayor proporción de compuestos volátiles, que son transformados en otras sustancias. Es la primera vez que se reporta un estudio de este tipo con un fruto tropical, como lo es Solanum quitoense Lam.

\section{Agradecimientos}

Al grupo de investigación "Estudio y aprovechamiento de productos naturales marinos y frutas de Colombia”, del Departamento de Química de la Universidad Nacional de Colombia, y a la Dirección de Investigaciones de la Uptc (DIN-Uptc), por el apoyo económico al proyecto SGI-1325.

\section{Referencias}

[1] C. Osorio, C. Duque, "Volátiles generados por hidrólisis enzimática de glicólisis de hojas de lulo (Solanum quitoense Lam)". Revista Co- lombiana de Química, vol. 4, no. 2, pp. 69-81, 1995.

[2] C. Osorio, C. Duque, Y. Fujimoto, "C13Norisoprenoid Glucoconjugates from Lulo (Solanum quitoense L.) Leaves". Journal of Agricultural and Food Chemistry, vol. 47, no. 4, pp. 1641-1645, 1999.

[3] B. J. Cabrera A. Caracterización del aroma del lulo (Solanum quitoense Lam). Universidad Nacional de Colombia, Bogotá, 1999.

[4] G. Alonzo, F. Saiano, N. Tusa, S. Fatta del Bosco, "Analysis of volatile compounds released from embryogenic cultures and somatic embryos of sweet oranges by head space SPME”. Plant Cell Tiss Organ Cult, vol. 66, no. 1, pp. 31-34, 2001.

[5] R. Niedz, M. Moshonas, B. Peterson, J. Shapiro, P. Shaw, "Analysis of sweet orange (Citrus sinensis (L.) Osbeck) callus cultures for volatile compounds by gas chromatography with mass selective detector". Plant Cell Tiss Organ Cult, vol. 51, no. 3, pp. 181-185, 1997.

[6] A. Mohagheghzadeh, M. Shams-Ardakani, A. Ghannadi, "Volatile constituents of callus and flower-bearing tops of Zataria multiflora Boiss. (Lamiaceae)". Flavour and Fragrance Journal, vol. 15, no. 6, pp. 373-376, 2000.

[7] T. H. Kim, J. H. Shin, H. H. Baek, H. J. Lee, "Volatile flavour compounds in suspension culture of Agastache rugosa Kuntze (Korean mint)". Journal of the Science of Food and Agriculture, vol. 81, no. 6, pp. 569-575, 2001.

[8] G. B. Lockwood, G. Asghari, B. Hakimi, "Production of essential oil constituents by cultured cells of Carum copticum L.". Flavour and Fragrance Journal, vol. 17, no. 6, pp. 456-458, 2002.

[9] P. C. Santos-Gomes, M. Fernandes-Ferreira, "Essential Oils Produced by in Vitro Shoots of Sage (Salvia officinalis L.). Journal of Agricultural and Food Chemistry, 51(8), pp. 22602266, 2003.

[10] A. Pavlov, S. Popov, E. Kovacheva, M. Georgiev, M. Ilieva, "Volatile and polar compounds in Rosa damascena Mill 1803 cell suspension". Journal of Biotechnology, vol. 118, no. 1, pp. 89-97, 2005. 
[11] A. Ahuja, S. K. Bakshi, S. K. Sharma, R. K. Thappa, S. G. Agarwal, S. K. Kichlu, R. Paul, M. K. Kaul, "Production of volatile terpenes by proliferating shoots and micropropagated plants of Santolina chamaecyparissus L. (cotton lavender)". Flavour and Fragrance Journal, vol. 20, no. 4, pp. 403-406, 2005.

[12] A. Chakraborty, S. Chattopadhyay, "Stimulation of menthol production in Mentha piperita cell culture". In Vitro Cell.Dev.Biol.-Plant, vol. 44, no. 6, pp. 518-524, 2008.

[13] V. R. Affonso, H. R. Bizzo, C. L. S. Lage, A. Sato, "Influence of Growth Regulators in Biomass Production and Volatile Profile of in Vitro Plantlets of Thymus vulgaris L.". Journal of Agricultural and Food Chemistry, vol. 57, no. 14, pp. 6392-6395, 2009.

[14] A. Grover, J. Yadav, R. Biswas, C. S. Pavan, P. Mishra, V. Bisaria, D. Sundar, "Production of monoterpenoids and aroma compounds from cell suspension cultures of Camellia sinensis". Plant Cell, Tissue and Organ Culture (PCTOC), vol. 108, no. 2, pp. 323-331, 2012.

[15] H. Passinho-Soares, P. Meira, J. David, P. Mesquita, A. Vale, F. de M. Rodrigues, P. de P. Pereira, J. de Santana, F. de Oliveira, J. de Andrade, J. David, "Volatile Organic Compounds Obtained by in Vitro Callus Cultivation of Plectranthus ornatus Codd. (Lamiaceae)". Molecules, vol. 18, no. 9, pp. 10320-10333, 2013.

[16] C. Osorio, C. Duque, F. Batista-Viera, "Studies on aroma generation in lulo (Solanum quitoense): enzymatic hydrolysis of glycosides from leaves". Food Chemistry, vol. 81, no. 3, pp. 333-340, 2003.

[17] M. Suárez, C. Duque, C. Bicchi, H. Wintoch, G. Full, P. Schreier, "Volatile constituents from the peelings of lulo (Solanum vestissimum D.) fruit". Flavour and Fragrance Journal, vol. 8, no. 4, pp. 215-220, 1993.

[18] F. Bourgaud, A. Gravot, S. Milesi, E. Gontier, "Production of plant secondary metabolites: a historical perspective". Plant Science, vol. 161, no. 5, pp. 839-851, 2001.

[19] W. Zhu, G. Asghari, G. B. Lockwood, "Factors affecting volatile terpene and non-terpene biotransformation products in plant cell cultures". Fitoterapia, vol. 71, no. 5, pp. 501-506, 2000.

[20] S. Ramachandra Rao, G. A. Ravishankar, "Plant cell cultures: Chemical factories of secondary metabolites". Biotechnology Advances, vol. 20, no. 2, pp. 101-153, 2002.

[21] J. T. Brown, P. K. Hegarty, V. B. Charlwood, "The toxicity of monoterpenes to plant cell cultures". Plant Science, vol. 48, no. 3, pp. 195201, 1987.

[22] H. C. Passinho-Soares, P. Meira, J. P. David, P. R. Mesquita, A. E. Vale, F. M. Rodrigues, P. Pereira, J. Raniere, F. Oliveira, J. B. Andrade, J. David, "Volatile organic compounds obtained by in vitro callus cultivation of Plectranthus ornatus Codd. (Lamiaceae)". Molecules, vol. 18, pp. 10320-10333, 2013.

[23] R. dee Alwis, K. Fujita, T. Ashitani, K. I. Kuroda, "Volatile and non-volatile monoterpenes produced by elicitor-stimulated Cupressus lusitanica cultured cells". Journal of Plant Physiology, vol. 166, no. 7, pp. 720-728, 2009.

[24] M. R. Zuzarte, A. M. Dinis, C. Cavaleiro, L. R. Salgueiro, J. M. Canhoto, "Trichomes, essential oils and in vitro propagation of Lavandula pedunculata (Lamiaceae)". Industrial Crops and Products, vol. 32, no. 3, pp. 580-587, 2010. 